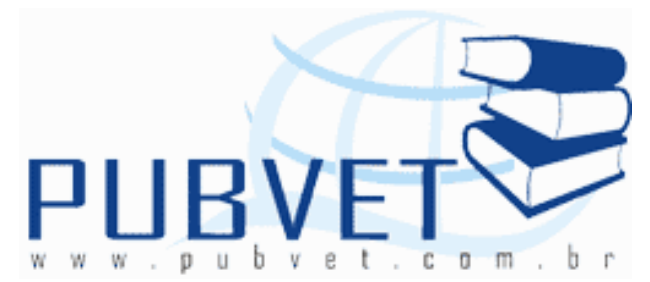

PUBVET, Publicações em Medicina Veterinária e Zootecnia.

\title{
Mentha crispa e fembendazol no tratamento de parasitoses: um estudo clínico
}

\section{Camila Zeferino Carlos $^{1}$, Poliana Ferraz Nunes ${ }^{1}$, Tainá da Silva ${ }^{1}$ Angélica do Rocio Carvalho Silva²}

${ }^{1}$ Graduanda em Medicina Veterinária - UNIFEOB - São João da Boa Vista ${ }^{2}$ Médica Veterinária - Doutora - Docente de Ensino Superior - UNIFEOB (São João Da Boa Vista) e FESB (Bragança Paulista)

\section{Resumo}

Os parasitas gastrointestinais são agentes patogênicos muito encontrados em animais de companhia, ocasionando sérios transtornos. Devido a sua incidência e resistência dos parasitas aos medicamentos comumente usados muitas plantas vêm sendo estudadas para serem usadas no tratamento de várias doenças, como por exemplo a Mentha crispa. O objetivo deste estudo foi avaliar o efeito da Mentha crispa comparativamente com o febendazole no tratamento de parasitoses em cães e gatos. Foram utilizados quatro cães e seis gatos para o tratamento com fembendazol e seis cães e cinco gatos, para a Mentha crispa. Como resultados, tanto o extrato de Mentha crispa como o fembendazole foram eficazes após a primeira administração contra os parasitos encontrados nos cães, exceto para Giardia sp., sendo no entanto eficazes contra esta espécie após a segunda administração. Para os gatos, os dois tratamentos utilizados não foram eficazes contra o protozoário, que foi o único 
CARLOS, C.Z. et al. Mentha crispa e fembendazol no tratamento de parasitoses: um estudo clínico. PUBVET, Londrina, V. 5, N. 39, Ed. 186, Art. 1257, 2011.

gênero de parasita encontrado nos animais dessa espécie doméstica avaliados neste estudo.

Palavras-chave: endoparasita, Mentha crispa, protozoário, febendazole, cão, gato.

\title{
Mentha crispa and fenbendazole in the treatment of parasitic: a clinical study
}

\begin{abstract}
The gastrointestinal parasites are pathogens found in pets, causing serious disorders. Due to its incidence and resistance to drugs commonly used many plants are being studied so they can be used in the treatment of several diseases, such as Mentha crispa. The purpose of this study was to evaluate the effect of Mentha crispa comparatively with fenbendazole in the treatment of parasitic infections in dogs and cats. We used four dogs and six cats for the treatment with fenbendazole and six dogs and five cats for Mentha crispa. As a result, both the extract of Mentha crispa and fenbendazole were effective after the first administration against the parasitc infections found in the dogs, except for Giardia $s p$, however, it was effective against this species after the second administration. For cats, both treatments were not effective against protozoan, the only genre of parasite found in these animals.
\end{abstract}

Keywords: endoparasitic, Mentha crispa, protozoan, fenbendazole, dog, cat.

\section{INTRODUÇÃO:}

Os parasitos intestinais estão entre os agentes patogênicos mais encontrados em animais de companhia e constituem uma das principais causas de transtornos intestinais em cães (BLAGBURN et al.,1996). Além dos problemas causados aos animais, muitos desses parasitos podem infectar 0 homem, como por exemplo a larva migrans visceral e a larva migrans cutânea causadas respectivamente por larvas de Toxocara spp. e Ancylostoma spp. 
CARLOS, C.Z. et al. Mentha crispa e fembendazol no tratamento de parasitoses: um estudo clínico. PUBVET, Londrina, V. 5, N. 39, Ed. 186, Art. 1257, 2011.

(FARIAS, CRISTOVÃO e STOBBE, 1995), sendo este um grande problema para a saúde publica (MIRÓ, 2007 apud AGENER UNIÃO, 2009). O tratamento adequado dos animais infectados por esses parasitos reduz o índice de zoonoses e beneficia a saúde animal (MIRÓ, 2007 apud AGENER UNIÃO, 2009).

Existem cerca de dezessete espécies de trematódeos, dezessete de cestódeos, vinte de nematódeos, uma de acantocéfalo e um grande número de protozoários que acometem os cães (EGUÍA-AGUILAR et al., 2005 apud KATAGIRI e OLIVEIRA-SIQUEIRA,2007), sendo que os mais comuns são Ancylostoma spp., Toxocara canis, Giardia sp. e Cryptosporidium spp., Neospora caninum (GENNARI et al., 1999 apud KATAGIRI e OLIVEIRASIQUEIRA, 2007). Em felinos os parasitas mais comuns são Ancylostoma spp. e Toxocara spp (BARROS et al.,2009).

Os maiores índices de prevalência de Giardia sp. são encontrados em animais jovens, principalmente até um ano de idade. Os animais castrados tendem a mostrar uma reduzida prevalência na infecção se comparados aos animais sexualmente ativos (BECK et al., 2005; SOUSA et al., 2003).

Muitas espécies de plantas tem sido pesquisadas para tratamento de doenças em animais. No entanto, os estudos buscando alternativas para o combate de parasitoses gastrointestinais estão entre os mais frequentes e dentre elas pode se citar a Mentha Crispa, que vem sendo utilizada no controle de giardíase (SILVA et al., 2008).

O objetivo deste trabalho é avaliar o efeito da Mentha crispa comparativamente com o fembendazole no tratamento de endoparasitoses em cães e gatos.

\section{REVISÃO BIBLIOGRÁFICA:}

Existem vários parasitas gastrointestinais que podem acometer os animais de companhia, cães e gatos, podendo causar-lhes grave sintomatologia clínica, desde desordens gastrintestinais como anorexia, diarréia, vomito, perda de peso e redução do ganho deste e até mesmo óbito, 
CARLOS, C.Z. et al. Mentha crispa e fembendazol no tratamento de parasitoses: um estudo clínico. PUBVET, Londrina, V. 5, N. 39, Ed. 186, Art. 1257, 2011.

principalmente se estes forem filhotes. Além do prejuízo causado a estes animais, existe também o risco de contaminação de seres humanos devido a seu potencial zoonótico, sendo necessário o conhecimento do proprietário sobre os cuidados necessários para manutenção da saúde e bem estar de sua família, onde o manejo e educação apropriada podem minimizar a transmissão destes parasitos (BALASSIANO, 2007).

Esses cuidados devem ser destacados, especialmente no Brasil, onde há um grande número de indivíduos vivendo em comunidades precárias em termos de habitação e saneamento básico, o que favorece a convivência promiscua, principalmente entre crianças e cães, e consequentemente a trasmissão zoonótica (KATAGIRI e OLIVEIRA-SIQUEIRA; 2007).

Em humanos, os parasitos podem promover graves infecções intestinais (LABRUNA et al., 2006), além das lesões por larva migrans cutânea, causada pelos parasitos responsáveis pela ancilostomíase e toxocaríase em cães e gatos, o que gera um grande problema de saúde pública (CÔRTES et al. 1988; LABRUNA et al., 2006).

Por estes motivos, o conhecimento do ciclo dos parasitas, é importante para o controle e tratamento das infecções causadas por eles, visando não apenas a saúde do animal, mas também a do homem.

A Giardia sp. é um protozoário que possui duas formas distintas, os trofozoítos flagelados (móveis) e os cistos infectantes (imóveis). É um protozoário entérico que afeta humanos, animais domésticos e animais selvagens (SILVA et al., 2008; FORTES, 2004; SHERDING, JOHNSON, 2003). Sua transmissão é feita através da ingestão de alimentos, ou de água, contendo cistos. O excistamento ocorre nas criptas do duodeno e cada cisto origina dois trofozoitos. Os trofozoítos se fixam às células epiteliais do intestino, pelo disco suctorial, e utilizam os produtos da digestão dos alimentos realizados pelo hospedeiro (FORTES, 2004a).

Ainda no intestino, os trofozoítos se encistam: recolhem os flagelos encurtam o corpo e segregam um cisto resistente hialino em torno de si. Os cistos maduros são eliminados pelas fezes, sendo infectantes e muito 
CARLOS, C.Z. et al. Mentha crispa e fembendazol no tratamento de parasitoses: um estudo clínico. PUBVET, Londrina, V. 5, N. 39, Ed. 186, Art. 1257, 2011.

resistentes e podendo permanecer viáveis no meio ambiente por até duas semanas (FORTES, 2004a).

Os trofozoítos, enquanto permanecem na mucosa intestinal, impedem a absorção das gorduras que ocorre nesse órgão, possivelmente alterando as enzimas do intestino delgado por mecanismo direto, ou por mudança do $\mathrm{Ph}$ (FORTES, 2004a).

Sabe-se que áreas com pH baixo favorecem o crescimento da Giardia $s p$. Entretanto o mecanismo de má absorção e a diarréia provocada pela infecção por este parasite ainda não estão esclarecidos (FORTES, 2004a).

A maioria dos animais com giardiase e são assintomáticos. Nos sintomáticos, apesar de o apetite apresentar-se normal, ocorre má digestão dos nutrientes, gerando fezes pálidas e fétidas, esteatorréia, diarréia crônica, perda de peso, ou pequeno ganho de peso (HALL, SIMPSON, 2006; BECK et al., 2005; SOUSA et al., 2003). Em filhotes, ocorre também atraso no crescimento devido à má absorção de nutrientes (BARATELLA,2007).

De acordo com Urquhart et al. (1996), o gênero Toxocara ocorre muito em carnivoros domésticos. A espécie Toxocaris leonina acomete cães e gatos e - Toxocara canis, apenas cães. Essas especies são macroscopicamente indistinguíveis, sendo o único aspecto de diferenciação entre os sexos, a presença de um processo digitiforme na ponta da cauda do macho.

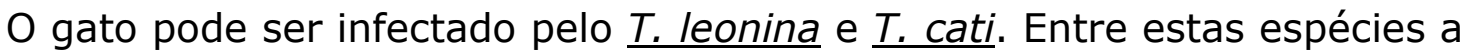
diferenciação baseia-se no formato das asas cervicais, lanceoladas no $\underline{T}$. leonina e em forma de pontas de flecha no $\underline{T \text {. cati }}$. O ciclo evolutivo de todos os parasitas deste gênero inicia-se pela ingestão do ovo contendo larvas de segundo estágio (L2), que eclode no intestino delgado e segue pela circulação sanguínea via fígado para os pulmões, tranformando-se em larva de terceiro estágio (L3). Esta retorna via traquéia para o intestino, onde ocorrem suas duas mudas finais. Este tipo de infecção ocorre apenas em cães com até três meses de idade. Em cães com mais de três meses de idade, a migração hepatotraqueal ocorre com menos freqüência, e aos seis meses, esse trajeto quase cessa. Então, as L2, podem completar o ciclo, seguindo para uma ampla 
CARLOS, C.Z. et al. Mentha crispa e fembendazol no tratamento de parasitoses: um estudo clínico. PUBVET, Londrina, V. 5, N. 39, Ed. 186, Art. 1257, 2011.

variedade de tecidos, incluindo o fígado, pulmão, cérebro, coração, musculatura esquelética e paredes do trato digestivo (URQUHART et al., 1996b).

A infecção por Toxocara em cães pode ocorrer também por via transplacentária, quando ocorre migração da L3 para o pulmão do feto. $\mathrm{O}$ filhote lactante também pode infestar-se por ingestão de L3 a partir do leite durante as três primeiras semanas (URQUHART et al., 1996b). Estes filhotes infectados completam o ciclo em três a quatro semanas após nascimento, quando são capazes de eliminar ovos de $\underline{T}$. canis junto com as fezes, para o meio ambiente (GLICKMAN, 1993 apud DAMIAN et al., 2007). Mas não existe migração no filhote após a infecção por essa via. E uma cadela, uma vez infectada, abriga larvas suficientes para infectar todas as ninhadas subseqüentes, mesmo que nunca mais entre em contato com o parasita (URQUHART et al., 1996).

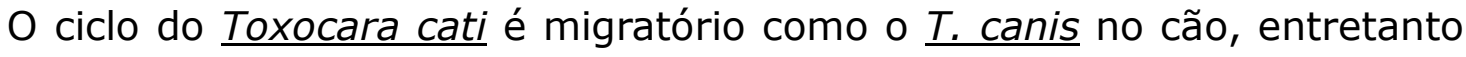
não ocorre infecção pré-natal (URQUHART et al., 1996b).

Segundo Armour et al. (1996) apud Urquhart et al. (1996), a família Ancylostomidae cujos membros são comumente denominados ancilóstomos, devido à deposição em gancho de suas extremidades anteriores, o que thes permite ampla mobilidade e motilidade, durante as suas atividades hematofógas no intestino delgado.

A espécie Ancylostoma caninum acomete cão e raposa; a $\underline{A}$. tubaeforme, gatos e a $\underline{A}$. braziliense acomete também as raposas. Este parasito é comum em áreas temperadas. O ciclo evolutivo do $\underline{\text { A.caninum }}$ pode ocorrer das seguintes maneiras. Em condições ideais os ovos podem eclodir e desenvolverse até $\mathrm{L} 3$ em um período de cinco dias. A infecção pode ocorrer por penetração cutânea ou ingestão. Na penetração cutânea, as larvas migram via circulação sanguínea para os pulmões, onde se tornam larvas de quarto estágio (L4), nos brônquios e na traquéia. Então são deglutidas e seguem para o intestino delgado onde ocorre a muda final. Se a infecção ocorrer por ingestão das larvas, pode haver penetração pela mucosa bucal e ocorrer migração 
CARLOS, C.Z. et al. Mentha crispa e fembendazol no tratamento de parasitoses: um estudo clínico. PUBVET, Londrina, V. 5, N. 39, Ed. 186, Art. 1257, 2011.

pulmonar, ou elas podem ir diretamente para o intestino delgado e tornaremse patentes. O período pré-patente e de quatorze a vinte e um dias e um cão infectado pode eliminar milhões de ovos. Em cadelas susceptíveis, uma proporção das L3 que atingiram os pulmões, migram para os músculos esqueléticos, onde permanecem latentes até a cadela ficar prenhe e parir, quando então, ainda como L3, são eliminadas no leite para os filhotes. Essa transmissão transmamária é responsável por anemia grave nos filhotes (URQUHART, 1996a).

Devido à ancilostomíase, pode ocorrer anemia hemorrágica aguda ou crônica em cães infectados, além das infecções cutâneas. Em cães jovens lactantes, a anemia seria mais grave e acompanhada por diarréia, com sangue e muco (URQUHART et al., 1996a).

O $A$. tubaeforme, que atinge gatos, tem um ciclo evolutivo muito semelhante ao $\underline{A}$. caninum, entretanto não há evidencias de transmissão transmamária (URQUHART,1996a).

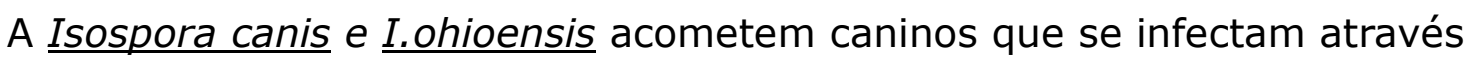
da ingestão de oocistos esporulados presentes em alimentos ou água contaminada, ou ainda por ingestão de vetores paratênicos infectados (ratos). Os oocistos liberam esporozoitos que invadem as células epiteliais do intestino grosso. Os esporozoitos sofrem esquizogonia gerando esquizontes que se tornam merozoitos e que, quando maturos, realizam gametogonia e fertilização eliminando oocistos nas fezes. Período pré-patente do parasita é de nove a onze dias (FORTES, 2004b).

A Isospora felis acomete felinos domésticos e selvagens, tendo como hospedeiros paratênicos, os ratos e camundongos. Os felinos são infectados pela ingestão dos oócitos esporulados, através de água, ou alimentos contaminados, e também do hospedeiro paratênico infectado. Os esporozoitos, uma vez livres invadem as células do hospedeiro e se localizam próximos ao núcleo das células epiteliais das vilosidades do ílio, duodeno e jejuno (WENYON, 1923 apud FORTES et al., 2004).

No camundongo (hospedeiro paratenico), a multiplicação do parasito é 
CARLOS, C.Z. et al. Mentha crispa e fembendazol no tratamento de parasitoses: um estudo clínico. PUBVET, Londrina, V. 5, N. 39, Ed. 186, Art. 1257, 2011.

limitada: a $\underline{I . \text { felis }}$ encista-se nos gânglios linfáticos, e fica viável por 23 meses (FORTES, 2004a).

Considerando aspectos do tratamento destas endoparasitoses Andrade e Santarém (2002) apresentam algumas famílias farmacológicas que atuam em diversos parasitas como os:

-Antinematódeos: que atuam em vermes de corpo redondo, e que apresentam dimorfismo sexual.

-Anticestódeos: que agem sobre vermes hermafroditas de corpo achatado, em forma de fita, divididos em segmentos denominados proglótides.

-Antitrematódeos: atuam sobre trematódeos, que são helmintos de corpo achatado sendo a maioria das espécies hemafroditas.

-Antiprotozoários: atuam sobre os protozoários, que são organismos unicelulares.

Dentre os antinematódeos podem ser citados os benzimidazois e probenzimidazois, que são representados pelo albendazol, febantel, febendazol, flubendazol, mebendazol, oxifebendazol, oxibendazol, tiabendazol e triclabendazol. Eles agem sobre os parasitas impedindo a síntese de microtubulos, que ocorre devido à inibição de betatubulina (ANDRADE e SANTARÉM, 2002). Os microtubulos são organelas ocas semelhantes a bastões, que fazem parte do citoesqueleto, mantendo o formato e estrutura da célula, além de possuir importante função na divisão celular (BANKS,1991). Devido a esta característica estes fármacos agem como larvicidas e adulticidas, atuando também na inibição do desenvolvimento embrionário das larvas (ANDRADE e SANTARÉM, 2002).

Alguns estudos têm demonstrado que anti-helminticos do grupo dos benzimidazois, como o albendazol e o fembendazol, são eficientes no tratamento de giardíase canina. Entretanto suspeita-se que o albendazol tenha efeito teratogênico não sendo recomendado para fêmeas prenhes (FERREIRA et al., 2006). O fembendazol é indicado para parasitoses (principalmente Giardia $s p$. ) por apresentar pequena incidência de efeitos adversos, baixo 
CARLOS, C.Z. et al. Mentha crispa e fembendazol no tratamento de parasitoses: um estudo clínico. PUBVET, Londrina, V. 5, N. 39, Ed. 186, Art. 1257, 2011.

custo, elevada eficácia e por seu uso ser autorizado em cães e gatos. Além disso, pode ser utilizado em fêmeas gestantes, no período pré natal e em cães jovens (AGENER UNIÃO,2009).

O fembendazol foi testado na dose de $50 \mathrm{mg} / \mathrm{kg} /$ dia durante três dias e mostrou-se eficiente para cães infectados por Giardia sp. (FERREIRA et al, 2006). Porém de acordo com Sherding, Johnson (2003), a associação de fembendazol e praziquantel (Panacur $®$ ) vem sendo associado à intoxicação na medula óssea.

Para os gatos podem ser usados anti-helmínticos de largo espectro como o fembendazol, para nematódeos gastrintestinais (Toxascaris leonina, Toxocara cati, Ancylostoma brasiliensis, Ancylostoma tubaeformis, Uncinaria stenocephala, Trichuris spp, Lagochilascaris major) e Giárdia sp. (MSD-Saúde Animal, 2011)

Os cães acometidos por Ancylostoma devem ser tratados com antihelminticos como o mebendazol, fembendazol e nitroscanato, pois todos destroem os parasitas em estágios adultos e em desenvolvimento que estejam nos intestinos. As ivermectinas também podem ser usadas, pois apresentam atividade semelhante (URQUHART et al., 1996a).

No tratamento de toxocariase, tanto em cães quanto em gatos a piperazina é a droga mais utilizada, embora esteja sendo substituída pelos benzimidazois como o fembendazol, mebendazol e por nitroscanato (URQUHART et al., 1996b).

Os parasitas podem adquirir resistência aos medicamentos, podendo esta, ser transmitida geneticamente, além de a taxa de resistência poder variar de acordo com o clima, as espécies de parasitas e os regimes de tratamentos. Um fator importante que pode gerar resistência nos parasitas é o uso de subdosagem medicamentosa, entretanto deve-se ter cuidado também com a superdosagem, sendo que esta pode levar à intoxicação e até à morte do animal (ANDRADE e SANTARÉM,2002).

Devido às questões ligadas a resistência dos parasitas, vem sendo muito pesquisado o uso de terapias alternativas, como a fitoterapia, onde utilizam-se 
CARLOS, C.Z. et al. Mentha crispa e fembendazol no tratamento de parasitoses: um estudo clínico. PUBVET, Londrina, V. 5, N. 39, Ed. 186, Art. 1257, 2011.

plantas para fins curativos (BERWICK, 1996 apud MARINHO et al.,2007). Seu surgimento na medicina veterinária ocorreu intuitivamente, observando os animais que quando doentes buscavam nas ervas a cura para suas afecções (OLIVEIRA e SILVA, 1994 apud MARINHO et al., 2007). Porém o uso indiscriminado de fitoterápicos pode trazer graves consequências como reações alérgicas, efeitos tóxicos em vários órgãos e até desenvolvimento de alguns tipos de câncer (CARLINI, 2004 apud MARINHO et al., 2007).

No trabalho de Silva et al. (2008) foi verificado o efeito do extrato de Mentha crispa no controle de giardíase em cães filhotes e adultos, detectados como positivos para esse parasito. Foram utilizadas duas dosagens $(5 \mathrm{ml}$ e 10 $\mathrm{ml}$ de xarope a base de Mentha crispa) para dois grupos (G1 e G2) de animais, que foram medicados uma vez ao dia, por três dias consecutivos. A dose de $10 \mathrm{ml}$ foi mais eficiente no controle da infeç̧ão do que a dose de $5 \mathrm{ml}$, já que com a dose de $10 \mathrm{ml} 100 \%$ dos animais (G1) apresentaram ausência de cistos e/ou trofozoítos de Giardia sp. nas fezes após o término do tratamento. Nos cães estudados, não foram observados efeitos adversos, nem tóxicos com o tratamento aplicado.

Em um estudo realizado por Barbosa (2009), foram selecionados 96 pacientes humanos portadores de Giardia lamblia que foram distribuídos aleatoriamente em dois grupos (G1 e G2) e tratados com: Secnidazol (50 pacientes tratados com $2 \mathrm{~g}$ de secnidazol -Secnidal $®$-G1), e Mentha crispa (46 pacientes medicados com $24 \mathrm{mg}$ de Mentha crispa - Giamebilß-G2). Os tratamentos foram administrados por via oral e em dose única. Após sete dias, avaliou-se a cura através do ensaio imunoenzimático (Elisa) em amostra fecal fresca. Observou-se que a taxa de cura do grupo Secnidazol $(84,00 \%)$ foi significantemente maior ( $\mathrm{P}=0,0002)$ que a verificada no grupo Mentha crispa $(47,83 \%)$. No entanto, as medicações foram bem toleradas, tendo ocorrido apenas três eventos adversos de intensidade leve, como a dor abdominal, que foi significantemente maior em indivíduos tratados com Mentha crispa. Entretanto, houve relatos de gosto metálico em ambos os grupos, sendo que foram mais frequentes no grupo Secnidazol. A ocorrência de náusea não diferiu 
significantemente entre os grupos. Conclui-se que na dose empregada, o efeito giardicida da Mentha crispa é inferior ao do secnidazol.

De acordo com Dimech (2003), o extrato bruto (EB) da Mentha crispa (principio ativo do Giamebil plus $\AA_{1}$ ) apresenta baixa toxicidade por via oral em ratos e camundongos. Ele realizou estudos de toxicologia pré-clinica, onde utilizou o extrato bruto da Mentha crispa administrado em camundongos e ratos por via oral $(0,1$ a $2,0 \mathrm{~g} / \mathrm{kg})$, não verificando alterações comportamentais em nenhuma das espécies. No experimento, foi feito também injeção do extrato por via intra peritonial (i.p.), onde o mesmo se mostrou tóxico, provocando a morte de $100 \%$ dos camundongos e $80 \%$ dos ratos. Foram realizados ainda, estudos de fertilidade em ratos de ambos os sexos e o tratamento com o EB $(0,5$ e $1,0 \mathrm{~g} / \mathrm{kg}$, v.o. $)$ durante 30 dias antes do acasalamento não induziu alterações significativas na relação prole/mãe. E o uso do mesmo tratamento durante o período de gestação, cerca de 20 dias, não produziu alterações no desenvolvimento embrionário, nem no desenvolvimento pós natal dos animais.

Ainda na mesma pesquisa, após administração por 30 dias de EB $(1,0 \mathrm{~g} / \mathrm{kg}$, v.o $)$ a camundongos, não ocorreram alterações perceptíveis à necropsia, nem no peso úmido dos animais, nem na morfologia macroscópica do coração, fígado, baço, rim, cérebro, pulmão, glândula adrenal, ducto deferente, testículo, ovário e útero. A microscopia e morfometria do coração, rim, córtex cerebral e genitálias acessórias, assim como os parâmetros bioquímicos e hematologicos também não tiveram alterações significativas (DIMECH, 2003).

\section{MATERIAIS E MÉTODOS:}

Foram coletadas fezes de 64 animais entre cães e gatos. Trinta cães eram oriundos de residências de três cidades do interior de São Paulo, cujos proprietários se disponibilizaram a participar do estudo. Trinta e quatro animais pertenciam a uma Associação de Proteção aos animais de outra cidade do 
CARLOS, C.Z. et al. Mentha crispa e fembendazol no tratamento de parasitoses: um estudo clínico. PUBVET, Londrina, V. 5, N. 39, Ed. 186, Art. 1257, 2011.

interior do mesmo Estado, sendo três cães e trinta e um gatos.

Nestas amostras, foi realizado exame coproparasitológico de Willis, para identificação de parasitos gastrintestinais. Os animais positivos $(32,81 \%)$ foram divididos em dois grupos (grupo $A$ e grupo $B$ ), relacionados à espécie $e$ ao porte físico dos mesmos, seu local de residência e manejo. Assim como apresentado nos quadros 1 e 2, o grupo A foi composto com cinco gatos e seis cães tratados com Xarope de Mentha crispa (quadro 1) e o grupo B foi formado por seis gatos e quatro cães medicados com fembendazole (Panacur ${ }^{\circledR}$ ) (quadro 2). Foram utilizados $10 \mathrm{ml}$, ou um comprido, de Mentha Crispa para do á cada cão e $5 \mathrm{ml}$, ou meio comprimido, para cada gato, por dia, durante três dias, repetindo o mesmo protocolo após quinze dias (Grupo A). O fembendazole foi usado na dose de $50 \mathrm{mg} / \mathrm{Kg}$ por dia, para cada animal durante três dias, repetindo o mesmo esquema após quinze dias (Grupo B). Foram realizados dois exames de fezes após as medicações: o primeiro após sete dias da primeira administração dos medicamentos, e o outro após sete dias da segunda administração.

Quadro 1- Caracterização dos animais do grupo A de acordo com sua espécie, peso corporal, local de residência, tipo de água ingerida, e compartilhamento ou não das vasilhas de bebida e comida.

GRUPO A-MENTHA CRISPA

\begin{tabular}{|l|l|l|l|l|l|l|}
\hline ANIMAIS & PESO & DOSAGEM & RESIDÊNCIA & CIDADE & ÁGUA INGERIDA & Vasilhas \\
\hline Cão 1 & $20 \mathrm{Kg}$ & $10 \mathrm{ml}$ & Zona Rural & Cidade 1 & Açude e encanada & Uso coletivo \\
\hline Cão 2 & $20 \mathrm{Kg}$ & $10 \mathrm{ml}$ & Zona Rural & Cidade 1 & Açude e encanada & Uso coletivo \\
\hline Cão 3 & $13 \mathrm{Kg}$ & $10 \mathrm{ml}$ & Zona Urbana & Cidade 2 & Encanada & Uso coletivo \\
\hline Cão 4 & $13 \mathrm{Kg}$ & $10 \mathrm{ml}$ & Zona Urbana & Cidade 2 & Encanada & Uso coletivo \\
\hline Cão 5 & $7,5 \mathrm{Kg}$ & $10 \mathrm{ml}$ & Zona Urbana & Cidade 3 & Encanada & Uso coletivo \\
\hline Cão 6 & $7,5 \mathrm{Kg}$ & $10 \mathrm{ml}$ & Zona Urbana & Cidade 3 & Encanada & Uso coletivo \\
\hline Gato 1 & $4,2 \mathrm{Kg}$ & $5 \mathrm{ml}$ & Zona Urbana & Cidade 3 & Encanada & Uso coletivo \\
\hline Gato 2 & $4,2 \mathrm{Kg}$ & $5 \mathrm{ml}$ & Zona Urbana & Cidade 3 & Encanada & Uso coletivo \\
\hline Gato 3 & $4,2 \mathrm{Kg}$ & $5 \mathrm{ml}$ & Zona Urbana & Cidade 3 & Encanada & Uso coletivo \\
\hline Gato 4 & $4,2 \mathrm{Kg}$ & $5 \mathrm{ml}$ & Zona Urbana & Cidade 3 & Encanada & Uso coletivo \\
\hline Gato 5 & $4,2 \mathrm{Kg}$ & $5 \mathrm{ml}$ & Zona Urbana & Cidade 3 & Encanada & Uso coletivo
\end{tabular}


CARLOS, C.Z. et al. Mentha crispa e fembendazol no tratamento de parasitoses: um estudo clínico. PUBVET, Londrina, V. 5, N. 39, Ed. 186, Art. 1257, 2011.

Quadro 2- Caracterização dos animais do grupo B de acordo com sua espécie, peso corporal, local de residência, tipo de água ingerida, e compartilhamento ou não das vasilhas de bebida e comida.

\begin{tabular}{|c|c|c|c|c|c|c|c|}
\hline \multicolumn{8}{|c|}{ GRUPO B-FEMBENDAZOL } \\
\hline ANIMAIS & PESO & DOSAGEM & RESIDÊNCIA & CIDADE & \multicolumn{2}{|c|}{ ÁGUA INGERIDA } & VASILHAS \\
\hline Cão 1 & $1 \mathrm{Kg}$ & $\begin{array}{l}\text { 1/4 comprimido } \\
\text { ( } 125 \mathrm{mg} / \mathrm{dia})\end{array}$ & Zona Rural & Cidade 1 & \multicolumn{2}{|l|}{ Encanada } & Uso coletivo \\
\hline Cão 2 & $2 \mathrm{Kg}$ & $\begin{array}{l}\text { 1/4 comprimido } \\
\text { (125mg/dia) }\end{array}$ & Zona Rural & Cidade 1 & \multicolumn{2}{|c|}{ Açude e encanada } & Uso coletivo \\
\hline Cão 3 & $4,5 \mathrm{Kg}$ & $\begin{array}{l}1 / 2 \text { comprimido } \\
\text { ( } 250 \mathrm{mg} / \mathrm{dia})\end{array}$ & Zona Urbana & Cidade 2 & \multicolumn{2}{|l|}{ Encanada } & Uso coletivo \\
\hline Cão 4 & $20 \mathrm{Kg}$ & $\begin{array}{l}2 \text { comprimidos } \\
\text { (1000mg/dia) }\end{array}$ & Zona Urbana & Cidade 3 & \multicolumn{2}{|l|}{ Encanada } & Uso coletivo \\
\hline Gato 1 & $4 \mathrm{Kg}$ & $\begin{array}{l}\text { 1/2 comprimido } \\
\text { ( } 250 \mathrm{mg} / \text { dia) }\end{array}$ & Zona Urbana & Cidade 3 & \multicolumn{2}{|l|}{ Encanada } & Uso coletivo \\
\hline Gato 2 & $4 \mathrm{Kg}$ & $\begin{array}{l}\text { 1/2 comprimido } \\
\text { ( } 250 \mathrm{mg} / \text { dia) }\end{array}$ & Zona Urbana & Cidade 3 & \multicolumn{2}{|l|}{ Encanada } & Uso coletivo \\
\hline Gato 3 & $4 \mathrm{Kg}$ & $\begin{array}{l}\text { 1/2 comprimido } \\
\text { ( } 250 \mathrm{mg} / \text { dia) }\end{array}$ & Zona Urbana & Cidade 3 & \multicolumn{2}{|l|}{ Encanada } & Uso coletivo \\
\hline Gato 4 & $4 \mathrm{Kg}$ & $\begin{array}{l}\text { 1/2 comprimido } \\
\text { ( } 250 \mathrm{mg} / \text { dia) }\end{array}$ & Zona Urbana & Cidade 3 & \multicolumn{2}{|l|}{ Encanada } & Uso coletivo \\
\hline Gato 5 & $4 \mathrm{Kg}$ & $\begin{array}{l}1 / 2 \text { comprimido } \\
\text { ( } 250 \mathrm{mg} / \text { dia) }\end{array}$ & Zona Urbana & Cidade 3 & Encanada & \multicolumn{2}{|c|}{ Uso coletivo } \\
\hline Gato 6 & $4 \mathrm{Kg}$ & $\begin{array}{l}\text { 1/2 comprimido } \\
\text { ( } 250 \mathrm{mg} / \text { dia) }\end{array}$ & Zona Urbana & Cidade 3 & Encanada & \multicolumn{2}{|c|}{ Uso coletivo } \\
\hline
\end{tabular}

\section{RESULTADOS:}

Nos quadros 3 e 4 são apresentados os resultados dos três primeiros exames coproparasitológicos dos animais positivos: o primeiro exame que os selecionou para serem tratados, e os dois outros exames após o tratamento e dose de repetição. No primeiro exame de fezes realizado após a primeira administração dos medicamentos, o grupo A, tratado com Mentha crispa (Giamebil plus $\AA$ ), obteve-se que dois cães e todos os gatos continuaram positivos para Giardia sp. (Quadro 3). 
CARLOS, C.Z. et al. Mentha crispa e fembendazol no tratamento de parasitoses: um estudo clínico. PUBVET, Londrina, V. 5, N. 39, Ed. 186, Art. 1257, 2011.

Quadro 3- Resultados do exame coproparasitológico dos animais do grupo A.

\section{GRUPO A- ANIMAIS TRATADOS COM MENTHA CRISPA}

\begin{tabular}{|c|c|c|c|}
\hline Animais & Exame Inicial & 10 exame & $2^{\circ}$ Exame \\
\hline Cão 1 & Toxocara/Giardia & Giárdia & - \\
\hline Cão 2 & Giardia/Isospora & Giárdia & - \\
\hline Cão 3 & Giardia & - & - \\
\hline Cão 4 & Giardia & - & - \\
\hline Cão 5 & Giardia & - & - \\
\hline Cão 6 & Giardia & - & - \\
\hline Gato 1 & Giardia & Giárdia & Giárdia \\
\hline Gato 2 & Giardia & Giárdia & Giárdia \\
\hline Gato 3 & Giardia & Giárdia & Giárdia \\
\hline Gato 4 & Giardia & Giárdia & Giárdia \\
\hline Gato 5 & Giardia & Giárdia & Giárdia \\
\hline
\end{tabular}

No grupo $B$, em que os animais foram tratados com Fembendazol (Panacur $\AA$ ), obteve-se após a primeira administração do medicamento, dois cães ainda positivos para Giardia $s p_{\text {., }}$ assim como todos gatos, positivos para este parasita, conforme o quadro 4 abaixo:

Quadro 4-Resultados dos exames coproparasitológicos do grupo B.

GRUPO B- ANIMAIS TRATADOS COM FEMBENDAZOL

\begin{tabular}{|l|l|l|l|}
\hline Animais & Exame Inicial & $\mathbf{1}^{\mathbf{0}}$ exame & \multicolumn{1}{c}{$\mathbf{2}^{\mathbf{0}}$ exame } \\
\hline Cão 1 & Giardia & - & Giárdia \\
\hline Cão 2 & Giardia & Giardia & - \\
\hline Cão 3 & Giardia & - & - \\
\hline Cão 4 & Giardia/Ancylostoma & Giárdia & - \\
\hline Gato 1 & Giardia & Giárdia & Giárdia \\
\hline Gato 2 & Giardia & Giárdia & Giárdia \\
\hline Gato 3 & Giardia & Giárdia & Giárdia \\
\hline Gato 4 & Giardia & Giárdia & Giárdia \\
\hline Gato 5 & Giardia & Giárdia & Giárdia \\
\hline Gato 6 & Giardia & Giárdia & Giárdia \\
\hline
\end{tabular}




\section{DISCUSSÃO E CONCLUSÃO:}

Os gatos tratados com Mentha crispa continuaram positivos para Giardia $\underline{s p}$. após as duas doses do medicamento. Isso pode ter ocorrido devido á ineficiência do composto e/ou da dosagem utilizada em gatos.

A primeira aplicação o extrato de Mentha crispa, em $10 \mathrm{ml}$, durante três dias, não se mostrou efetivo para o controle de Giardia sp. em cães, ao contrario do trabalho de Silva et al (2008), em que o tratamento com a mesma dosagem e números de dias mostrou-se efetivo em $100 \%$ dos cães. Portanto o tratamento foi repetido após 15 dias, como prescrito para o fembendazol quando então o fitoterápico mostrou-se efetivo para $100 \%$ dos cães com giardiase. No entanto, contra os demais parasitos encontrados no exame coproparasitológico inicial (Isospora sp e Toxocara sp), a Mentha crispa utilizada com protocolo proposto por Silva et al. (2008) foi eficaz.

O fenbendazole teve a resposta esperada para os cães, no que se refere ao controle dos parasitas (Giardia $s p$., Ancylostoma $s p$. ) encontrados no exame coproparasitológico inicial.

O fato de ele, assim como o extrato de Mentha crispa terem sido mais eficazes contra Giardia $s p$. após a segunda administração, pode estar relacionado com o fato do cisto infectante ser resistente no meio ambiente, prenecendo viável por até duas semanas, conforme aponta Fortes (2004).

E a ocorrência de um animal que se manteve positivo para giardíase mesmo após a repetição do fenbendazole pode estar ligada a falta de saneamento básico, indo de encontro ao que Katagiri, Oliveira-Siqueira (2007) afirmaram em relação a disseminação desta zoonose em situações onde não há medidas básicas de saneamento, pois este animal tinha acesso livre a um açude, ingerindo água do mesmo.

Em relação à eficácia do fenbendazole contra Giardia sp. em gatos, a maioria dos animais permaneceram positivos. Podendo ser devido a grande população de animais na mesma gaiola, com comedouros e bebedouros 
CARLOS, C.Z. et al. Mentha crispa e fembendazol no tratamento de parasitoses: um estudo clínico. PUBVET, Londrina, V. 5, N. 39, Ed. 186, Art. 1257, 2011.

comuns, favorecendo assim a transmissão do parasita e reinfecção pelo mesmo.

Pode-se verificar que tanto o extrato de Mentha crispa como o fembendazole foram eficazes, após a primeira administração, contra os parasitos encontrados nas fezes dos cães, exceto no caso de Giardia sp., sendo no entanto eficazes contra esta espécie após a segunda administração, com exceção de um caso, onde o manejo do animal pode ter influído no resultado. Estes resultados podem demonstrar maior resistência da Giardia $s p$. aos tratamentos, ou maior taxa de reinfecção por este agente. E no que se refere aos felinos, talvez se deva reavaliar o manejo e os protocolos parasiticidas utilizados, a fim de obter a eficácia almejada.

\section{REFERÊNCIAS:}

AGENER UNIÃO. Utilizações técnicas-O Uso de fembendazol na clínica de pequenos animais. Divisão saúde animal da união química farmacêutica nacional S/A. Acesso em: http://www.posgraduacao.ufla.br/residencia/gauss/conteudo/fenzol.pdf, 2009.

ANDRADE, S.F.; SANTARÉM,V.A. Endoparasiticidas e Ectoparasiticidas In ANDRADE, S.F., Manual de Terapêutica Veterinária. 2 Ed. ROCA. 2002, p.440-460.

BALASSIANO, B.C.C. Fatores Associados a Infecção Natural de Cães por Parasitos Gastrintestinais. Tese. Universidade Federal Rural do Rio de Janeiro -Instituto de Veterinária. Seropédica Rio de Janeiro, 2007.

BANKS, W. J. Células - Estrutura e Função. Histologia veterinária aplicada. 2 Ed, Manole.1991, p.46-48.

BARATELLA, T.F. Diarréia em cães neonatos - Principais etiologias. Monografia. Curso de Medicina Veterinária - UNIFEOB, 2007.

BARBOSA,N.S. Avaliação da eficácia terapêutica da Mentha crispa no tratamento da giardiase. Dissertação. Mestrado em Farmacologia-Universidade Federal do Ceará. Disponível em: <http://servicos.capes.gov.br/capesdw/resumo.html?idtese $=2008922001018007$ P7> Acesso em: 26/10/2009.

BARROS,F.N;NEVES M.L.M.W, ALVES L.C.; FAUSTINO M.A.G.Avaliação da Eficácia AntiHelmíntica da Formulação Emodepsida/Praziquantel em Felinos.Anais IX Jornada de Ensino Pesquisa e Extensão.Universidade Federal Rural de Pernanbuco,2009.

BARTMANN, A. Freqüência de Giardiase lamblia (Kunstler,1882) em cães (Canis familiaris) determinada através de exames parasitológicos solicitados por clinicas veterinarias da cidade de Porto Alegre Rio Grande do Sul. Dissertação. Mestrado em Ciências VeterináriasUniversidade Federal do Rio Grande do Sul Disponível em <http://servicos.capes.gov.br/capesdw/resumo.html?idtese $=200218542001013030$ P5 > Acesso em 29/05/2009. 
BECK, C.; ARAÚJO, F.A.P.; OLICHESKI, A.T. BREYER, A.S. Freqüência da infecção por Giárdia lamblia (Kunstler,1882) em cães (Canis familiaris) avaliada pelo método de Faust e cols.(1930) e pela coloração de Aramina, no município de Canoas, RS, Brasil. Ciência Rural v.35, n.1, p.126-130, 2005.

BLAGBURN, B.L.; LINDSAY, D.S.; VAUGHAN, J.L.; RIPPEY, N.S.; WRIGHT, J.C.; LYNN, R.C.; KELEH, W.J.; RITCHIE, G.C.; HEPLER, D.I. Prevalence of canine parasites based on fecal flotation. The Compendium on Continuing Education for the Practicing Veterinarian, v.18, n.5, p.483-509, 1996.

CÔRTES, V.A.; PAIM, G.V.; ALENCAR FILHO, R.A. Infestações por Ancilostomídios e Toxocarídios em Cães e Gatos Apreendidos em Vias Públicas, São Paulo (Brasil). Revista de Saúde Pública. São Paulo, v.22, n.4, p.341-343, 1988.

DAMIAN, M. M.; MARTINS, M.; SARDINHA, J. F.; SOUZA, L. O.; CHAVES, A.; TAVARES, A. M. Freqüência de anticorpo anti-Toxocara canis em comunidade do Rio Uatumã, no Estado do Amazonas. Revista do Instituto de Medicina Tropical de São Paulo, v. 40, p. 661-664, nov-dez, 2007.

DIMECH, G.S. Avaliação toxicológica pré-clínica do extrato bruto da Mentha crispa. Dissertação. Mestrado em Ciências Biológicas (Fisiologia)-Universidade Federal de Pernambuco. Disponível em: <http://servicos.capes.gov.br/capesdw/resumo.html?idtese $=20035525001019011 \mathrm{P} 2>$ Acesso em: 26/10/2009.

FARIAS, N.A.; CRHISTOVÃO, M.L.; STOBBE, N.S. Frequência de Parasitas Intestinais em Cães (Canis Familiaris) e Gatos (Felis Catus Domestica) em Araçatuba-São Paulo. Revista Brasileira de Parasitologia. n.4,v.1, p.57-60, 1995.

FERREIRA, A.J.P.; PIZARRO, L.D.C.R.; PORTO, A.D. Tratamento anti-helminticos. In: SPNOSA, H.S.; GORNIAK, S.L.; BERNARDE, M.M. Farmacologia aplicada em medicina veterinária. São Paulo: Guanabara Koogan. 2006. v.4,p.564-565.

FORTES, E. Protozoologia. In: FORTES, E. Parasitologia Veterinária. São Paulo: 4 Ed. Cone, 2004. p.85-87a.

FORTES, E. Protozoologia. In: FORTES, E. Parasitologia Veterinária. São Paulo: 4 Ed. Cone, 2004. p.113-114b.

HALL,E.J.; SIMPSON,K.W. Doenças do Intestino Delgado. In: ETTENGER,S.J.; FELDMAN,E.C. Tratado de Medicina Interna Veterinária Doenças do cão e do gato. São Paulo: Guanabara Koogan. 2006. v.2, p1289.

KATAGIRI, S.; OLIVERA-SIQUEIRA,P.C.G. Zoonoses Causadas Por Parasitas Intestinais de Cães e o Problema do Diagnóstico, Botucatu, Brasil. Instituto Biológico v.74, n.2, p.175-184, 2007.

LABRUNA,M.B.;PENA,H.F.J.;SOUZA,S.L.P.;PINTER,A. ;SILVA,J.C.R.;RAGOZO, A.M.A.; CAMARGO, L.M.A.; GENNARI,S.M. Prevalência de Endoparasitas em Cães da Área Urbana do Minicípio de Monte Negro, Rondônia. Arquivos do Instituto Biológico, São Paulo, v.73, n.2, p.183-193, 2006.

LORENZINI,G.;TASCA,T.;CARLI,G. Prevalência de parasitas intestinais em cães e gatos sob cuidado veterinário em Porto Alegre, Rio Grande do Sul, Brasil. Brazilian Journal of Veterinary Research and Animal Science v.44, n.2, p.137-145, 2007. 
MSD - Saúde Animal. Panacur @ comprimidos - resumo da bula. Disponível em: $<$ http://www.msd-saude-

animal.com.br/products/PANACUR COMPRIMIDOS/020 Resumo da Bula.aspx> Acessado em: 21/05/2011.

MARINHO, M.L.; ALVES, M.S.; RODRIGUES, M.L.C.; ROTONDANO, T.E.F.; VIDAL, I.F.; SILVA, W.W.; ATHAYDE, A.C.R. A Utilização de Plantas Medicinais em Medicina Veterinária: Um resgate do Saber Popular. Revista Brasileira de Plantas Medicinais v.9, n.3, p.64-69, 2007.

SHERDING, R.G.; JOHNSON, S.E. Enteropatias. In: SHERDING, R.G.; BICHARD, S.J. Clinica de Pequenos Animais. São Paulo: ROCA. $2^{\circ}$ ed., p.873-874,2003.

SILVA,C.S.;MOREIRA,A.H. ;BENIGNO,R.N.M.,BITTENCOURT,R.H.P.M.;SOUSA,S.K.S.A. ;MOREIRA, V.M.T.S. Efeito do extrato de Mentha crispa no controle da giardiase em cães (Canis familiaris). Congresso Brasileiro de Medicina Veterinária - Sociedade de veterinários do Rio Grande do Sul$$
\text { Anais. }
$$$$
\text { Disponível }
$$

em:

<http://www.sovergs.com.br/conbravet2008/anais/cd/resumos/R0185-2.pdf>.Acesso em 29/05/2009.

SOUSA, S.Z. MUNDIM, M.J.S. CURY, M.C. HORTÊNCIO, S.M. Determinação da prevalência de giárdia sp e estudo comparativo de duas técnicas de diagnostico, utilizando-se fezes de cães procedentes de canis de Uberlândia-Minas Gerais. Horizonte Cientifico-A revista eletrônica da PROPP 2 ed, 2003.

URQUHART, G.M.; DUNCAN,J.L. DUNN,A.M. JENNINGS,F.W. Helmintologia veterinária. In: URQUHART,G.M. DUNCAN,J.L. DUNN,A.M. JENNINGS,F.W. Parasitologia Veterinária. Guanabara Koogan $2^{\circ}$ ed., p.46-48,1996a.

URQUHART,G.M.; DUNCAN,J.L. DUNN,A.M. JENNINGS,F.W. Helmintologia veterinária In: URQUHART,G.M. DUNCAN,J.L. DUNN,A.M. JENNINGS,F.W. Parasitologia Veterinária. Guanabara Koogan 2 ed., p.60-63,1996b. 